\title{
Optimization of PID parameters for controlling DC motor based on the aquila optimizer algorithm
}

\author{
Widi Aribowo, Supari, Bambang Suprianto \\ Department of Electrical Engineering, Universitas Negeri Surabaya, Surabaya, Indonesia
}

\begin{tabular}{l} 
Article Info \\
\hline Article history: \\
Received Jul 9, 2021 \\
Revised Jan 19, 2022 \\
Accepted Jan 25, 2022 \\
\hline
\end{tabular}

Keywords:

Aquila optimizer

Artificial intelligence

DC motor

Metaheuristic

Proportional integral derivative

\begin{abstract}
This study presents the application of the aquila optimizer (AO) algorithm to determine the parameters of the proportional integral derivative (PID) controller to control the speed of a dc motor. The AO method is inspired by the most popular bird of prey in the northern hemisphere named Aquila. Initially, the proposed AO algorithm is applied to unimodal and multimodal benchmark optimization problems. To get the performance of the AO method, the controller is compared with other methods, namely Seagull optimization algorithm (SOA), marine predators algorithm, giza pyramids construction (GPC), and chimp optimization algorithm (ChOA). The results represent that the $\mathrm{AO}$ is promising and shows the effectiveness. Determination of PID parameters using the AO method for dc motor speed control system shows superior performance.
\end{abstract}

This is an open access article under the CC BY-SA license.

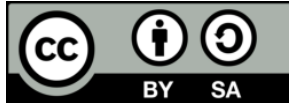

\section{Corresponding Author:}

Widi Aribowo

Department of Electrical Engineering, Universitas Negeri Surabaya

Unesa Ketintang Campus, Surabaya 61256, East Java, Indonesia

Email: widiaribowo@unesa.ac.id

\section{INTRODUCTION}

Power system control is a key role in fulfilling electricity needs. In addition, the increased complexity of the load is also a concern [1]. Direct current (DC) motors are included in the category of types of motors that are most widely used in industrial environments, household appliances to as supporting devices for electronic instrument systems [2]. In a control system, there are several types of control actions, including proportional, integral, and derivative control actions. Each of these control actions has certain advantages. Proportional-integral-derivative (PID) controller is a combination of the three types of controllers. If each of the three types of controllers is independent, the results achieved will not be good because each has its own strengths and weaknesses [3].

Different controllers are used to control the speed of the DC motor. The most widely used controllers are conventional PI and PID controllers. PIDs are widely used in conjunction with DC Motors in industrial applications. This control system works by processing calculations based on the control variables $\mathrm{Kp}, \mathrm{Ki}$, and $\mathrm{Kd}$ to achieve the conditions according to the expected setpoint. The PID is able to produce a good output response from the DC motor rotational speed [4]. However, its implementation of adjusting PID parameters is complex. In recent years there have been many methods for tuning PID parameters. In a simple application, a trial-error tuning method is used to adjust the PID value. However, this method is difficult to obtain optimal values. So, it is difficult to adjust the parameters, and it takes a long time and also the control accuracy is not good [5]. In recent years, researchers have used many artificial intelligent methods to optimize the parameters of DC motors, such as particle swarm optimization algorithm [6]-[8], Harris Hawks optimization [9], [10], genetic algorithm [11]-[13], firefly algorithm [14]-[16], flower pollination algorithm [17]-[19] and neural network [20]-[21]. 
This paper will present DC motor control using PID which is optimized using the an aquila optimizer (AO) algorithm. The AO was introduced by Abualigah [22]. Aquila optimizer (AO) duplicates the behavior of aquila in nature during the process of capturing prey. The aquila is one of the most popular birds of prey in the northern hemisphere [22]. The contribution of this paper is:

- The application of the latest and promising metaheuristic methods namely An Aquila Optimizer algorithm (AO) to set the PID parameters in DC motors

- The achievement of the offered method is tested by comparing it with the seagull optimization algorithm (SOA), marine predators algorithm, giza pyramids construction (GPC), and chimp optimization algorithm (ChOA).

This paper has an arrangement, namely the second part, which is about the concept of DC Motor and the aquila optimizer (AO) method. The third part is the results and discussion. The last part is to draw conclusions from the research.

\section{MATERIALS AND METHODS}

\subsection{DC motor}

DC motor is controlled by armature and field [23]. The stator and rotor are important parts of a DC motor. The non-rotating part of the DC motor is namely the stator. Rotor is the rotating piece. DC motor with anchor control uses armature current as of the controlling variable [24]. The stator field is generated by permanent magnets or current coils. The motor torque equation is as follows ( $\tau \mathrm{m})$.

$$
\begin{aligned}
& \tau \mathrm{m}(s)=\left(K_{1} K_{f} I_{f}\right) I_{a}(s)=K_{m} I_{a}(s) \\
& T_{m}(s)=K_{m} I_{a}(s)
\end{aligned}
$$

Where $K_{m}$ is The permeability function of the magnetic material [25]. The armature current $\left(I_{a}\right)$ and input voltage $\left(V_{a}\right)$ have a relationship in the armature circuit the equation is as follows,

$$
\begin{aligned}
& V_{a}(s)=\left(R_{a}+L_{a} \cdot s\right) \cdot I_{a}(s)+e_{b}(s) \\
& e_{b}(s)=K_{b} \omega(s)
\end{aligned}
$$

where $\mathrm{R}_{\mathrm{a}}$ and $\mathrm{L}_{\mathrm{a}}$ are Armature resistance and Armature inductance. $e_{b}$ is back electromotive force.

$$
\begin{aligned}
& \tau_{m}(s)=\tau_{L}(s)+\tau_{d}(s) \\
& \tau_{L}(s)=J s \omega(s)+B \omega(s)
\end{aligned}
$$

Where $\tau_{L}$ is the torque jointed to the load. $\tau_{d}$ is Fault torque. $J$ is inertia of the DC motor and $B$ is damping friction ratio. The block diagram of a DC motor can be seen in Figure 1.

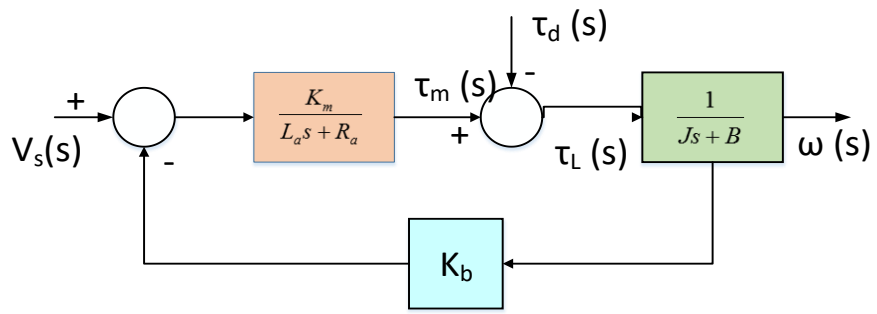

Figure 1. DC motor block diagram [26]

\subsection{An aquila optimizer}

Similar to all birds, Aquila has a dark brown coloration and behind the neck is more golden brown. Aquila has speed and agility. In addition, the Aquila has strong legs and sharp claws. this supports catching a variety of prey. Aquila has been recognized as an adult deer attack. Aquila builds large nests in mountains or other high positions. Aquila is one of the most intelligent and skilled hunters after humans. Like population- 
based algorithms, the AO method begins with a population of candidate solutions $(X)$. The method starts stochastically with an upper limit $(U B)$ and a lower limit $(L B)$ [22]. Each iteration will determine approximately the optimal solution, which is called the best solution.

$$
\begin{aligned}
& X=\left[\begin{array}{cccc}
X_{1,1} & \cdots \cdots & X_{1, n} \\
X_{2,1} & \cdots & \cdots & X_{2, n} \\
\vdots & \vdots & \vdots & \vdots \\
X_{m, 1} & X_{m, n} & \cdots & X_{m, n}
\end{array}\right] \\
& X_{i j}=\operatorname{rand} \times\left(U B_{j}-L B_{j}\right)+L B_{j}, i=1,2 \ldots \ldots, m j=1,2, \ldots \ldots n
\end{aligned}
$$

Where $m$ is the total number of candidate solutions (population), and $n$ is the dimension size of the problem. rand is a random number, the $\mathrm{j}$ th lower bound is $L B_{j}$. the $\mathrm{j}$ th upper bound of the given problem is $U B_{j}$. $\mathrm{AO}$ algorithm methods that simulate the behavior of aquila during hunting can be grouped into four steps:

- Step 1: Increased exploration $\left(X_{1}\right)$

In step 1, aquila explores from the sky to determine the area of the search space to determine the position of prey. Aquila identifies prey areas and selects the best areas for hunting.

$$
\begin{aligned}
& X_{1}(t+1)=X_{\text {best }}(t)\left(1-\frac{t}{T}\right)+\left(X_{M}(t)-X_{\text {best }}(t) \times \text { rand }\right) \\
& X_{M}(t)=\frac{1}{N} \sum_{i=1}^{N} X_{i}(t), N=1,2, \ldots . \operatorname{dim}
\end{aligned}
$$

Where, the solution of the next iteration of $t$ is $X_{1}(t+1)$. It is produced in the initial search method $\left(X_{1}\right)$. $X_{\text {best }}(t)$ Is the best-obtained solution until $t$ the iteration, this describes the estimated point of the prey. The parameter to supervisor the increased exploration via the number of iterations is $\left(1-\frac{t}{T}\right)$. The points mean value of the current solutions linked at $t$ th iteration is $X_{M}(t)$. rand is a random value. The dimension size of the problem is $\mathrm{dim}$. The population size is $N$.

- Step 2: Limited exploration $\left(X_{2}\right)$

In the second step, the prey has been found with a high level of altitude. In this position, Aquila will circle in the clouds, get into position, and prepare to attack prey. At this step, aquila has selected the area of prey. Mathematically, the second step can be formulated in (11)-(18).

$$
\begin{aligned}
& X_{2}(t+1)=X_{\text {best }}(t) \times \text { Levy }(D)+X_{R}(t)+(y-x) \times \text { rand } \\
& \text { Levy }(D)=s \times \frac{u \times \sigma}{|v| \frac{1}{\beta}} \\
& \sigma=\left(\frac{\Gamma(1+\beta) \times \operatorname{sine}\left(\frac{\pi \beta}{2}\right)}{\Gamma\left(\frac{1+\beta}{2}\right) \times \beta \times 2 \frac{\left(\frac{\beta-1}{2}\right)}{2}}\right) \\
& y=r \times \cos (\theta) \\
& x=r \times \sin (\theta) \\
& r=r_{1}+U+D_{1} \\
& \theta=-\omega \times D_{1}+\theta_{1} \\
& \theta_{1}=\frac{3 \times \pi}{2}
\end{aligned}
$$

Where the completion of the iteration $t$ produced by the second step of the method is $X_{2}(t+1)$. he distribution function of levy flights is $\operatorname{Levy}(D)$. the dimension space is $(D) . X_{R}(t)$ is a random solution value with a range of 1 to N. $s$ is a fixed constant value with a range up to $0.01 . u$ and $v$ are a random value between 0 and 1. $\sigma$ is a fixed constant value with a range up to 1.5. $x$ and $y$ are used to describe the spiral shape in the search. $r_{1}$ is selected a value between 1 and 20 which is used to fix the number of search cycles. 
$U$ is the variable multiplied by $0.00565 . D_{1}$ is an integer from 1 to the maximum value of the search space variable (dim). $\omega$ is a variable that has a fixed small value multiplied by 0.005 .

- Step 3: Increased exploitation $\left(X_{3}\right)$

In step 3, Aquila will be in a position of exploitation that is approaching the prey and giving a preemptive attack. This behavior can be represented mathematically by the (19).

$$
X_{3}(t+1)=\left(X_{\text {best }}(t)-X_{R}(t)\right) \times \alpha-\text { rand }+((U B-L B) \times \text { rand }+L B \times \delta
$$

Where the exploitation adjustment parameters fixed in this paper with small values $(0,1)$ are $\alpha$ and $\delta$. UB indicates the upper limit and $L B$ indicates the lower limit of the given problem.

- Step 4: Limited exploitation $\left(X_{4}\right)$

In method 4, aquilla gets closer to the prey. Prey will be attacked by aquilla on the ground. Aquilla walk on the ground and take prey. Prey is attacked by aquilla at the last location. Behavioral modeling of aquilla in step 4 can be modeled mathematically as in (20)-(23).

$$
\begin{aligned}
& X_{4}(t+1)=Q_{f} \times X_{\text {best }}(t)-\left(G_{1} \times X(t) \times \text { rand }\right)-G_{2} \times \operatorname{Levy}(D)+\operatorname{rand} \times G_{1} \\
& Q_{f}=t \frac{2 \times \text { rand }-1}{(1-T)^{2}} \\
& G_{1}=2 \times \text { rand }-1 \\
& G_{2}=2 \times\left(1-\frac{t}{T}\right)
\end{aligned}
$$

Where the solution of the iteration generated by the fourth search method $\left(X_{4}\right)$ is $X_{4}(t+1)$. The quality function used to balance the search strategy is $Q_{f}$. All kind of aquila movements used to track prey is $G_{1}$. $G_{2}$ is a lowering worth from 2 to 0. It is showed the flight incline of the Aquila applied to adhere prey from the first spot to the last spot. The current solution at the $\mathrm{t}$-th iteration is $X(t)$. A random point with range between 0 and 1 is rand. The current iteration is $t$. The maximum number of iterations is $T$. The allocation function of the flight levy is $\operatorname{Levy}(D)$.

\subsection{The proposed AO for tuning Dc motor}

To get adaptive control for dc motors, especially at points such as overshoot, rise-time, and settling time. PID parameters are searched and determined using the AO method. Figure 2 is an illustration of the AO method in determining the PID parameters on a DC motor. The detail of DC Motor parameters can be seen in Table 1.

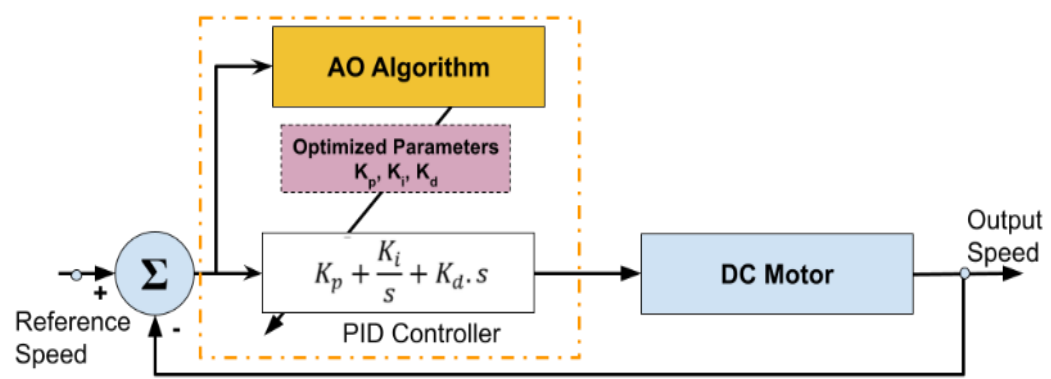

Figure 2. Proposed method diagram

Table 1. DC motor parameters

\begin{tabular}{cc}
\hline Parameter & Value \\
\hline Back emf constant $\left(K_{b}\right)$ & $0.01 \mathrm{~N}-\mathrm{m} / \mathrm{Amp}$ \\
Armature resistance $(\mathrm{R})$ & $2 \Omega$ \\
Armature inductance $(L)$ & $0.25 \mathrm{H}$ \\
Mechanical inertia $(J)$ & $0.02 \mathrm{Kg} / \mathrm{m} 2$ \\
Friction coefficient $(B)$ & $0.05 \mathrm{Nm} / \mathrm{rmp}$ \\
\hline
\end{tabular}




\section{RESULTS AND DISCUSSION}

AO Algorithm was written and simulated using MATLAB/Simulink on a laptop device with an intel i5 $(2.2 \mathrm{GHz})$ processor and $8 \mathrm{~GB}$ Ram. Table 2 is the detail of AO variable. To view the potency of the AOPID, it is compared with SOA, MPA, ChOA, and GPC. The global optima function is used to set the achievement of the AO method. Figure 3 is the convergence curve. The parameters of the SOA, MPA, GPC, ChOA, and AO methods were used to obtain parameters from the PID. Details of the PID parameters of each algorithm can be seen in Table 3. The PID data is used to control the DC motor.

The DC motor speed step response with speed reference 1 for SOA-PID, MPA-PID, ChOA-PID, GPC-PID, and AO-PID controllers is shown in Figure 4. Details regarding the step response of SOA-PID, MPA-PID, ChOA-PID, GPC-PID and AO-PID can be seen in Table 4. The proposed AO-PID has the best reaction step because it has the fastest constancy. Integral total time-weighted square of error (ITSE) and integral total weighted absolute value error (ITAE) were used to measure the performance of AO-PID. The ITSE and ITAE equations are as follows:

$$
\begin{aligned}
& \text { ITAE }=\int_{0}^{\infty} t \cdot e(t) \cdot d t \\
& \text { ITSE }=\int_{0}^{\infty} t \cdot e^{2}(t) \cdot d t
\end{aligned}
$$

Table 2 Parameter Of AO

\begin{tabular}{lc}
\hline \multicolumn{1}{c}{ Parameter } & Value \\
\hline Solution Number & 20 \\
Maximum Iterations & 50 \\
Lower Bound & 0 \\
Upper Bound & 10 \\
Dim & 4 \\
\hline
\end{tabular}

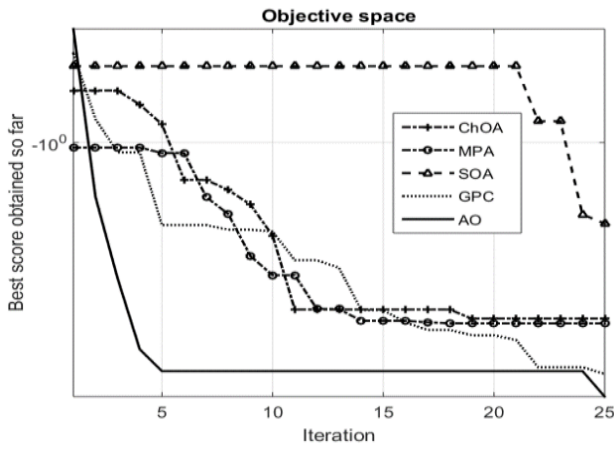

Figure 3. The convergence curve of benchmark function
Tabel 3 The result PID value

\begin{tabular}{cccc}
\hline Method & P & I & D \\
\hline PID & 2.8908 & 9.9239 & 0.1259 \\
SOA & 3.1251 & 10 & 0 \\
MPA & 3.18366 & 10 & 2.477545 \\
GPC & 2.6571 & 9.8923 & 0.1297 \\
ChOA & 3.2061 & 10 & 0.1699 \\
AO & 3.18025 & 10 & 0 \\
\hline
\end{tabular}

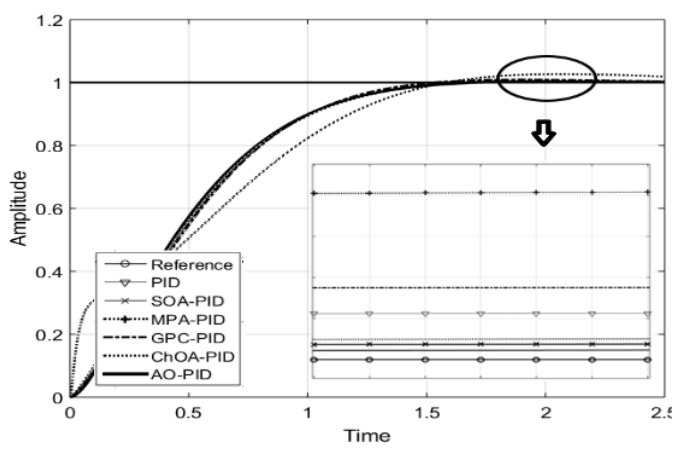

Figure 4. Step response with speed reference 1

Table 4. Comparison result with reference speed 1

\begin{tabular}{cccccc}
\hline Controller & Overshoot & Rise Time & Settling Time & ITSE & ITAE \\
\hline PID & 1.0066 & 1.811 & 2.771 & 0.3069 & 0.7944 \\
SOA-PID & 1.0037 & 1.774 & 2.809 & 0.2939 & 0.7633 \\
MPA-PID & 1.0269 & 2.413 & 3.15 & 0.3563 & 1.140 \\
GPC-PID & 1.0092 & 1.796 & 2.711 & 0.3155 & 0.8091 \\
ChOA-PID & 1.0045 & 1.841 & 2.841 & 0.2958 & 0.7828 \\
AO-PID & 1.0032 & 1.777 & 2.829 & 0.2924 & 0.7631 \\
\hline
\end{tabular}

The comparison of the ITAE and ITSE with the other controllers can be seen in Table 4. The ITAE value of the AO-PID has a value of 0.7631. It is the lowest ITAE value. The ITSE value for the AO-PID method is 0.2924 . Meanwhile, the highest value of ITSE is owned by the MPA-PID method, namely 0.3563 . To test the robustness of the proposed method, a test was carried out by changing the speed of the DC motor. The reference speed is set to the initial value of 0.8 for 5 seconds. Next, the reference speed is increased to 1 for 10 seconds. Finally, the reference speed is decreased by 0.5 . In Table 5, the overshoot and undershoot values can be seen in detail. In the first step, the highest overshoot value is MPA-PID, which is 0.8215 . On 
the other hand, AO-PID method has the lowest value. It is 0.8026. In step 2, the highest overshoot value is owned by the MPA-PID method of 1.005. In the second step, the overshoot value of the AO-PID and SOAPID methods differs very slightly, which is 0.0001 . In the third step, the reference speed is reduced by 0.5 . The worst undershoot value is by the MPA-PID method. It is 0.4864 . In Table 5, the AO has the same ITSE value as the ChOA method, which is 0.3482 . The lowest ITSE value is owned by the MPA method is 0.3468 . ITSE highest score is GPC with a value of 0.3486. The AO and SOA methods have the same ITAE value with a value of 0.7387 . The highest score of ITAE is owned by the MPA method, which is 0.7398 . On the other hand, the lowest value of ITAE is the GPC method of 0.7384 .

Table 5. Comparison results by changing the reference speed

\begin{tabular}{cccccccc}
\hline Controller & Overshoot Step 1 & Overshoot Step 2 & Undershoot Step 3 & Rise Time & Settling Time & ITSE & ITAE \\
\hline PID & 0.8053 & 1.0014 & 0.4968 & 0.854 & 12.71 & 0.3483 & 0.7385 \\
SOA-PID & 0.8029 & 1.0006 & 0.4984 & 0.8 & 12.77 & 0.3484 & 0.7387 \\
MPA-PID & 0.8215 & 1.005 & 0.4864 & 1.139 & 14.99 & 0.3468 & 0.7398 \\
GPC-PID & 0.8074 & 1.002 & 0.4954 & 0.867 & 12.65 & 0.3486 & 0.7384 \\
ChOA-PID & 0.8036 & 1.0008 & 0.4979 & 0.849 & 12.79 & 0.3482 & 0.7388 \\
AO-PID & 0.8026 & 1.0005 & 0.4985 & 0.798 & 12.79 & 0.3482 & 0.7387 \\
\hline
\end{tabular}

\section{CONCLUSION}

DC motor control is a very interesting field due to the rapid development of control methods. Weak parameter adjustment will result in de motor performance. In this study, the Aquila Optimizer Algorithm method was proposed to optimize the parameters of the PID. In conclusion, the AO method has optimal achievement. The proposed method can reduce the overshoot of the PID by an average of $0.023 \%$ and can improve the undershoot of the PID by $0.5 \%$. The proposed method, namely AO which is applied to optimize PID controllers, has the best ability.

\section{REFERENCES}

[1] W. Aribowo, B. Suprianto, A. Buditjahjanto, I. G. P. Widyartono, and M. Rohman, "An Improved Neural Network Based on Parasitism-Predation Algorithm for an Automatic Voltage Regulator," ECTI Transactions on Electrical Engineering, Electronics, and Communications, vol. 19, no. 2, pp. 136-144, 2021, doi: 10.37936/ecti-eec.2021192.241628.

[2] S. N. Al-Bargothi, G. M. Qaryouti, and Q. M. Jeber, "Speed control of DC motor using conventional and adaptive PID controllers," Indonesian Journal of Electrical Engineering and Computer Science, vol. 16, no. 3, pp. 1221-1228, 2019, doi: 10.11591/ijeecs.v16.i3.pp1221-1228.

[3] W. Aribowo, S. Muslim, B. Supriant, S. I. Haryudo, and A. C. Hermawan, "Intelligent Control of Power System Stabilizer Based on Archimedes Optimization Algorithm-Feed Forward Neural Network," International Journal of Intelligent Engineering and Systems, vol. 14, no. 3, pp. 43-53, 2021, doi: 10.22266/ijies2021.0630.05.

[4] J. Viola, L. Angel, and J. M. Sebastian, "Design and robust performance evaluation of a fractional order PID controller applied to a DC motor," IEEE/CAA Journal of Automatica Sinica, vol. 4, no. 2, pp. 304-314, 2017, doi: 10.1109/JAS.2017.7510535.

[5] Z. Qi, Q. Shi, and H. Zhang, "Tuning of Digital PID Controllers Using Particle Swarm Optimization Algorithm for a CAN-Based DC Motor Subject to Stochastic Delays,” IEEE Transactions on Industrial Electronics, vol. 67, no. 7, pp. 5637-5646, 2020, doi: 10.1109/TIE.2019.2934030.

[6] J. Agarwal, G. Parmar, R. Gupta, and A. Sikander, "Analysis of grey wolf optimizer based fractional order PID controller in speed control of DC motor," Microsystem Technologies, vol. 24, no. 12, pp. 4997-5006, 2018, doi: 10.1007/s00542-018-3920-4.

[7] W. Xie, J. S. Wang, and H. B. Wang, "PI controller of speed regulation of brushless DC motor based on particle swarm optimization algorithm with improved inertia weights," Mathematical Problems in Engineering, vol. 2019, ID. 2671792, 2019, doi: $10.1155 / 2019 / 2671792$.

[8] M. A. Mughal, M. Khan, A. A. Shah, and A. A. Almani, "Parameter estimation of DC motor using chaotic initialized particle swarm optimization," Proc. 3rd Int. Conferences on Electromechanical Control Technology and Transportation, Chongqing, China, 2018. pp. 19-21, doi: 10.5220/0006971403910395.

[9] V. K. Munagala and R. K. Jatoth, "Design of Fractional-Order PID/PID Controller for Speed Control of DC Motor Using Harris Hawks Optimization," Intelligent Algorithms for Analysis and Control of Dynamical Systems, pp. 103-113, 2021, doi: 10.1007/978-981-15-8045-1_11.

[10] S. Ekinci, D. Izci, and B. Hekimoğlu, "PID Speed Control of DC Motor Using Harris Hawks Optimization Algorithm," International Conference on Electrical, Communication, and Computer Engineering (ICECCE), 2020, pp. 1-6, doi: 10.1109/ICECCE49384.2020.9179308.

[11] E. F. Morán, W. Y. Pazmiño, and J. B. Monteses, "Genetic algorithm and fuzzy self-tuning PID for DC motor position controllers," 19th International Carpathian Control Conference (ICCC), 2018, pp. 162-168, doi: 10.1109/CarpathianCC.2018.8399621.

[12] E. H. Putra, Z. Has, and M. Effendy, "Robust Adaptive Sliding Mode Control Design with Genetic Algorithm for Brushless DC Motor," 5th International Conference on Electrical Engineering, Computer Science and Informatics (EECSI), 2018, pp. 330-335, doi: 10.1109/EECSI.2018.8752768.

[13] D. K. Meena and S. Chahar, "Speed control of DC servo motor using genetic algorithm," International Conference on Information, Communication, Instrumentation and Control (ICICIC), 2017, pp. 1-7, doi: 10.1109/ICOMICON.2017.8279122.

[14] B. N. Kommula and V. R. Kota. "Direct instantaneous torque control of Brushless DC motor using firefly Algorithm based fractional order PID controller," Journal of King Saud University-Engineering Sciences, vol. 32, no. 2, pp.133-140, 2020, doi: 10.1016/j.jksues.2018.04.007. 
[15] G. K. Rajput et al., "Design of TID controller based on firefly algorithm for controlling the speed of a DC Motor," E3S Web of Conferences, 2020, vol. 184, no. 01038, pp. 1-5, doi: 10.1051/e3sconf/202018401038.

[16] R. Klempka and B. Filipowicz, "Optimization of a DC Motor Drive Using a Firefly Algorithm," International Symposium on Electrical Machines (SME), 2018, pp. 1-6, doi: 10.1109/ISEM.2018.8442512.

[17] D. Puangdownreong, "Fractional order PID controller design for DC motor speed control system via flower pollination algorithm," ECTI Transactions on Electrical Engineering, Electronics, and Communications, vol. 17, no. 1, pp. 14-23, 2019, doi: 10.37936/ecti-eec.2019171.215368.

[18] M. Mahmud, S. M. A. Motakabber, A. H. M. Z. Alam, and A. N. Nordin, "Utilizing of flower pollination algorithm for brushless dc motor speed controller," Emerging Technology in Computing, Communication and Electronics (ETCCE), 2020, pp. 1-5, doi: 10.1109/ETCCE51779.2020.9350866.

[19] D. Potnuru, K. A. Mary, and C. S. Babu, "Experimental implementation of Flower Pollination Algorithm for speed controller of a BLDC motor,” Ain Shams Engineering Journal, vol. 10, no. 2, pp. 287-295, 2019, doi: 10.1016/j.asej.2018.07.005.

[20] S. C. Chen and C. Y. Kuo, "Design and implement of the recurrent radial basis function neural network control for brushless DC motor," International Conference on Applied System Innovation (ICASI), 2017, pp. 562-565, doi: 10.1109/ICASI.2017.7988483

[21] M. Khatri, P. Dahiya, and A. Hussain, "Performance Analysis of Separately Excited DC Motor with Wavelet Neural Network based Controller," 3rd International Conference on Intelligent Sustainable Systems (ICISS), 2020, pp. 503-507, doi: 10.1109/ICISS49785.2020.9316015.

[22] L. Abualigah, “Aquila Optimizer: A novel meta-heuristic optimization Algorithm,” Computers \& Industrial Engineering, vol. 157, no. 107250, 2021, doi: 10.1016/j.cie.2021.107250.

[23] B. A. Obaid, A. L. Saleh, and A. K. Kadhid, "Resolving of optimal fractional PID controller for DC motor drive based on antiwindup by invasive weed optimization technique," Indonesian Journal of Electrical Engineering and Computer Science, vol. 15, no. 1, pp. 95-103, 2019, doi:10.11591/ijeecs.v15.i1.pp95-103.

[24] W. Aribowo, S. Bambang, and Joko, "Improving neural network using a sine tree-seed algorithm for tuning motor DC," International Journal of Power Electronics and Drive System (IJPEDS). 2021, vol. 12, no. 2, pp. 1196-1204, 2021, doi: 10.11591/ijpeds.v12.i2.pp1196-1204.

[25] S. J. Hammoodi, K. S. Flayyih, and A. R. Hamad, "Design and implementation speed control system of DC Motor based on PID control and Matlab Simulink," International Journal of Power Electronics and Drive System (IJPEDS), vol. 11, no. 1, pp. 127-134, 2020, doi: 10.11591/ijpeds.v11.i1.pp127-134.

[26] M. S. Amiri, M. F. Ibrahim, and R. Ramli, "Optimal parameter estimation for a DC motor using genetic algorithm," International Journal of Power Electronics and Drive System (IJPEDS), vol. 11, no. pp. 1047-1054, 2020, doi: 10.11591/ijpeds.v11.i2.pp1047-1054.

\section{BIOGRAPHIES OF AUTHORS}

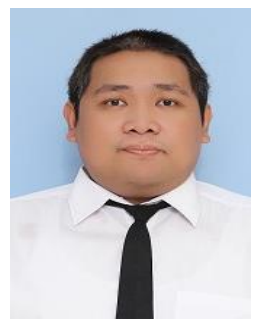

Widi Aribowo (D) SC $\mathrm{P}$ is a lecturer in the Department of Electrical Engineering, Universitas Negeri Surabaya, Indonesia. He is B.Sc in Power Engineering/Sepuluh Nopember Institute of Technology (ITS) - Surabaya in 2005. He is M.Eng in Power Engineering/Sepuluh Nopember Institute of Technology (ITS) - Surabaya in 2009. He is mainly research in the power system and control. He can be contacted at email: widiaribowo@unesa.ac.id.

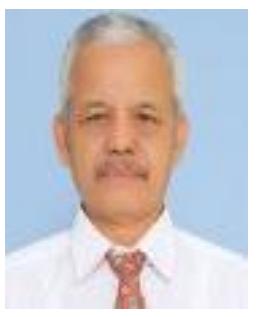

Supari Muslim (D) SC P is a lecturer in the Department of Electrical Engineering, Universitas Negeri Surabaya, Indonesia. He completed Bachelor of Electronic Engineering Education in Universitas Negeri Surabaya - Surabaya in 1979. He was completed Doctor in Universitas Negeri Yogyakarta - Malang in 1995. His research interests include power system and motor. He can be contacted at email: supari@unesa.ac.id

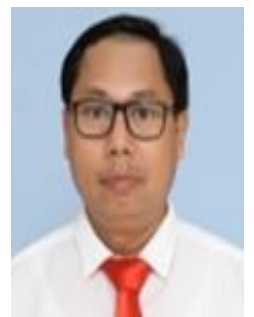

Bambang Suprianto (D) SC P is a lecturer in the Department of Electrical Engineering, Universitas Negeri Surabaya, Indonesia. He completed Bachelor of Electronic Engineering Education in Universitas Negeri Surabaya - Surabaya in 1986. He holds Master Engineering in Sepuluh Nopember Institute of Technology (ITS) - Surabaya in 2001. He was completed Doctor of Electrical Engineering in Sepuluh Nopember Institute of Technology (ITS)-Surabaya in 2012. His research interests include power system, control and electronic. He can be contacted at email: bambangsuprianto@unesa.ac.id 